\title{
Assessment of Students' Academic Performance Using Admission Entry Requirements under the Computer-Based Test and Paper-Pencil-Based Test in Kaduna State University, Kaduna - Nigeria
}

\author{
Sa'adatu Abdulkadir \\ Department of Computer Science, Nigerian Defence Academy (NDA), Kaduna, Nigeria \\ Email: saa.abdul@ymail.com \\ Emmanuel Amano Onibere \\ Department of Computer Science, Nigerian Defence Academy (NDA), Kaduna, Nigeria \\ Email: eonibere2000@gmail.com \\ Philip Oshiokhaimhele Odion \\ Department of Computer Science, Nigerian Defence Academy (NDA), Kaduna, Nigeria \\ Email: podion2012@gmail.com
}

Received: 12 June 2019; Accepted: 01 July 2019; Published: 08 August 2019

\begin{abstract}
The study aimed to assess whether the students from mathematical science-based undergraduate degree programmes in Kaduna State University perform academically better when either the Computer-Based Test (CBT) or the Paper-Pencil Test (PPT) is used to write the Unified Tertiary Matriculation Examination (UTME), which is conducted annually by the Joint Admissions Matriculation Board (JAMB). The study adopted a quantitative approach to research. A purposive sample of one thousand and twenty-three (1023) first-year students constituted the population for the study. This population was drawn from Computer Science, Mathematics and Physics undergraduate degree programmes in the Kaduna State University who were admitted from the 2010/2011 to $2012 / 2013$ and $2015 / 2016$ to $2016 / 2017$ academic sessions respectively. The instruments used for data collection were the UTME scores and the academic standing of first-year Cumulative Grade Point Average (CGPA) results, which were coded and analysed with the aid of Computational Statistical Package for Social Sciences (SPSS) version 23. Descriptive statistics and Analysis of Variance (ANOVA) were the statistical tools used to answer the four (4) research questions raised. The results revealed a majority of the students who performed academically better were those who used the PPT as their test medium in writing the UTME. It concluded that the majority of the students who wrote the UTME using PPT performed better in their academics. The study thereby recommended that there is a need for the Joint Admissions Matriculation Board (JAMB) to review its examination policies in mathematics-based subjects to
\end{abstract}

enable students to pass such subjects with flying colours, thereby encouraging them to perform better academically in the undergraduate studies.

Index Terms - Computer-Based Test, Paper-Pencil Test, Unified Tertiary Matriculation Examination.

\section{INTRODUCTION}

Students are the most indispensable asset for any schools, colleges and universities [1]. Education enables individuals and society to make all-around participation in the development process by acquiring knowledge, ability, skills, interests, competencies and attitudes. There is a need to produce the best quality graduates who will become great leaders and also produce enough human resources [2] for social and economic development in any of the countries in the world. It also ensures that the skills and knowledge acquired enable individuals to intensify their productivity and also improve their quality of life. In Nigeria today, there is a continuous surge of demand to acquire university education [3]. As a result, students must undergo serious academic scrutiny by writing various entrance examinations, such as the Senior Secondary School Examination (SSCE) conducted yearly by the West Africa Examination Council or the National Examination Council (NECO) and also with the UTME conducted every year by JAMB. These must be written and passed before they get admitted into any of the Nigerian tertiary educational institutions such as 
Universities, Polytechnics, Colleges of Education and other similar institutions. Each student is expected to have passed all the relevant examinations as well as other requirements by the departments into which a student is seeking admission. These examinations determine the extent to which educational goals have been achieved as well as the extent to which educational institutions have served the needs of community and society [4].

Due to the rapid advancement of Information and Communication Technologies (ICTs) in education, the paradigm, which has shifted from paper-pencil-based to computer-based system of examinations [5] which are usually termed as Computer Based Testing (CBT), Computer Assisted Testing, Computer Based Assessment (CBA), Computer Aided Assessment (CAA), EAssessment, Online Assessment, Web-Based assessment and many others. ICT has also been used as an essential tool for assessments in military training, and certification examinations by professional groups and promotional examinations in various stages and categories of life [6].

During the past few years, the method of assessment has been significantly reshaped by technology. In much academic domain, educational measurement has been moving toward the use of CBT which is defined merely by [7] as tests and assessments conducted through the use of the organised systems on computers. Computer-Based tests can automate a very time-consuming task such as marking and monitoring progress. As cited in [7], by Chalmers who sees Computer Based Test as "a test that can be used in a supervised or non-supervised environment and can allow students to check their progress through self-assessment".

Since the year 2013, there has been a sharp departure from the traditional paper-and-pencil mode of examinations due to the inclusion of ICT in education. Institutions like JAMB and some tertiary educational institutions in Nigeria thereby had to reconsider and review or change the traditional examination methods by introducing Computer Based Testing (CBT) as a new assessment model. CBT examinations are used to promote learning that is more effective by testing a range of skills, knowledge and understanding among students and this has also reduced the burden of examiners by conducting the examinations at ease.

The UTME is a test conducted by JAMB to select qualified candidates for admissions into Nigerian tertiary institutions. The examination usually comprises of 23 subjects including the Use of English (UOE) and is conducted at different times within 14 days for over 1.5 million candidates. Therefore the UTME is compulsory for any candidate seeking admission into any tertiary institution in Nigeria.

In 2012, the JAMB Executive Registrar, Professor Dibu Ojerinder announced that with effect from 2013, candidates would have the option of writing UTME as a paper and pencil test (PPT), Dual Based Test (DBT) where candidates answer questions displayed on the screen on paper or Computer Based Test (CBT). These methods of writing the UTME were adopted for only two years where the paper-based test had problems and challenges such as "high production cost of writing materials, transportation of materials at a high cost so as to curb examination malpractices, flexibility and speediness of processing results, a decline in cheating and conformity with global trends" [8]. The problems and challenges encountered later on became opportunities, which were used to address and perfect the process of the UTME and its CBT.

In 2015, JAMB adopted CBT as the only method to conduct examinations with a total of $1,475,477$ candidates in more than 400 centers nationwide as well as in seven foreign centers located at Accra (Ghana), Buea (Cameroon), Cotonou (Benin Republic), London (United Kingdom), Jeddah (Saudi Arabia), Johannesburg (South Africa) and Addis Ababa (Ethiopia) [8]. This is because in 2014, during the registration of the UTME, 616,574 candidates out of $1,606,753$ opted to write their examinations using the CBT. This indicates the readiness of all prospective candidates to adopt technological changes in the world, especially in the ICT. The primary objective why JAMB adopted the use of CBT to conduct examinations is to eliminate all forms of examination malpractices that had been a significant challenge in the conduct of paper pencil examination in the country and also promote the use of electronic testing in Nigeria. By eliminating the use of PPT examination in JAMB totally, the Federal Ministry of Education is expected to also introduce the use of CBT in other examination bodies in Nigeria such as National Examination Council (NECO), West African Examination Council (WAEC), National Business and Technical Examination Board (NABTEB) and National Teachers Institute (NTI) amongst others [9].

\section{A. Statement of the Problem}

There have been some poor performance rates year-inyear-out in the mathematical sciences-based bachelor's degree programmes at Kaduna State University such as Mathematics, Computer Science and Physics. "Ref. [10]" mentioned that these subjects are vital for an energetic technological society. The academic performance of some students has not been to their expectations. This has lead students to spending extra years before they could graduate with a pass degree at best or be withdrawn from the University due to the lapse of the given probation period or examination misconduct.

As the availability of technology in classrooms increases and as lecturers become more technologically inclined, it is essential they understand how switching from paper-based to computer-based tests may affect students performance.

\section{B. Aims and Objectives of Study}

The study aims to investigate whether the academic performance of students who were admitted in KASU using either CBT or PPT method during the JAMB UTME perform better academically.

The objectives of this study are to:

i. Obtain data using one of the fact-finding techniques. 
ii. Investigate, using statistical software, the use of CBT and PPT in the JAMB UTME by students wanting to pursue any of the mathematical science-based undergraduate programmes in the Kaduna State University.

iii. Recommend the best test method, either CBT or PPT that gives a better academic performance.

\section{Significance of Study}

The results of the study will be relevant to students, researchers, academics, management of secondary schools and tertiary institutions and other regulatory bodies, such as JAMB, WAEC, NECO and others, who are mandated to conduct an entrance examination to students. From the secondary schools and tertiary institutions management perspective, the findings of this study could help the management, teachers and lecturers to develop better strategies in addressing challenges faced by the students in the use of ICT and computers to solve mathematical questions within a time frame.

The regulatory bodies could do further research on most secondary schools and tertiary institutions to come up with a better solution to solve such challenges as generally, the majority of students in secondary schools and tertiary institutions are academically weak in Mathematics as a subject.

The student will benefit from the recommendations of this study aimed at improving their academic performance with the aid of CBT and other educational tools such as the Computer Aided Learning (CAL).

\section{Scope of Study}

As at the time of this study, data were available for the $2005 / 2006$ to $2017 / 2018$ academic sessions. However, only five years of collected data were analysed, 2010/2011, 2011/2012, 2012/2013, 2015/2016 and $2016 / 2017$, because the others were having incomplete data. Additionally, the study focused on full-time students in the mathematical science-based undergraduate programmes because they are the target audience for the study. The demographic characteristics, JAMB UTME scores and CGPA results were limited to those data readily available in the University's central database and departmental examination officers (DEOs).

\section{E. Limitations of Study}

This study examined the data of students in the mathematical science-based undergraduate programmes. Data were not collected for every student for the 2010/2011, 2011/2012, 2012/2013, 2015/2016 and 2016/2017 academic sessions due to incomplete required data. Additionally, data collected for the 2013/2014 and 2014/2015 could not be analysed because, during those two years, some used the CBT to write the examinations while others used either the PPT or the DBT.

\section{F. Research Questions}

The study sought to find answers to the following research questions:-
1. Is there a significant difference in students' academic performance by using either of the testing methods, CBT or PPT in JAMB for Kaduna State University?

2. Is there a significant difference between male and female students' academic performance by using either of the testing methods, that is CBT or PPT in JAMB for Kaduna State University?

3. Is there a significant difference between Kaduna State indigene and Non-Kaduna State indigene students' academic performance by using either of the testing methods, that is CBT or PPT in JAMB for Kaduna State University?

4. Is there a significant difference between the academic performance of students in various age groups by using either of the testing methods, that is CBT or PPT in JAMB for Kaduna State University?

\section{RELATED WORKS}

Several studies have compared PPT and CBT. Some have found little to no difference between PPT and CBT $[11,12,13]$. Others have found students' academic performance to be lower on CBT relative to PPT. These differences in student performance have been linked to technological differences such as a CBT requiring scrolling [11, 12], and to participate characteristics for example the students' ethnicity, gender, or primary language $[14,15]$. Academic performance as defined by [24], is the knowledge attained or skill developed in the school subjects usually designated by test scores or by marks assigned by teachers. Some of the sources will be discussed in this section in chronological order.

"Ref. [16]" researched to find the difference in performance between a computer and paper-administered tests in a stressful environment. Their study aimed to determine whether stress plays a significant role in performance on computer and paper administered tests. In order to do so, a paper and online version of the Graduate Record Examinations' (GRE) verbal reasoning section were administered to 15 participants from the Physiology 435 course offered at the University of Wisconsin-Madison, while simultaneously being asked to squeeze a dynamometer every 30 seconds for ten minutes. A galvanic skin response sensor, a pulse oximeter, and a dynamometer, which were all hooked to the participant's fingers, were used to observe the possibility of increased stress levels. While the stress-induced environment may not have been as stressful as expected, the data gathered and analysed using one-way ANOVA, suggested that there is no difference in performance between computer and paper tests.

"Ref. [17]" researched to compare student performance on Computer-Based versus Paper-Based Test in one of the first-year Engineering courses titled Fundamentals of Engineering at the Ohio State University. There are many benefits for the instructor to use computer-based exams 
instead of paper-based exams, which include automated grading, reduction of paper usage, ease of distribution and the ability to see student exam statistics instantly. Their study consisted of two midterm exams and a final exam conducted during the fall semester. The exam questions were in the form of multiple choice, multiple select, true/false and fill-in-the-blanks. Each exam consisted of two parts where each student took with either on a paper or a computer. The findings showed that the differences in the exam score between paper and computer were not statistically significant in 5 out of 6 exam parts, which were analysed using the Wilcoxon rank-sum test. There was a great inclination for the paper exams $(86 \%)$ over the computer exams $(5 \%)$ by the students. These results indicated that the students prefer the paper exams despite having similar performance to their computer counterparts. As a result of the performance being similar, it was recommended that future studies should explore ways of improving the student experience in the computer exam environment while still realising the advantages of computer-based examinations.

In [18], a study was conducted on the Comparability of Test Results of Computer-Based Tests (CBT) and PaperPencil Tests (PPT) among English Language Learners in Iran. Their study examined the score comparability of institutional multiple-choice reading comprehension tests in two testing methods that are the PPT and CBT, which were administered to the Iranian first-year English students in Azad University of Tehran, Iran. To find the results, the researcher needed to examine the impact of CBT on the test score results and also explore the relationship between particular test takers' characteristics such as prior computer familiarity and computer attitudes as well as test performance with their test scores. Two tests, which were similar, were administered on two different occasions to participants. Using the matched ttest to compare the means of two test modes, the findings of the study showed the priority of PPT over CBT. However, using ANOVA, the findings revealed that based on computer familiarity and attitude towards the computer, there is no significant influence on the students" performance in the computerised test. The study suggested that the results could be applied to other universities and language institutions.

"Ref. [15]" of Project 2061 stated, "despite the increasing acceptance of computer-based testing at all education levels, some questions about whether scores generated by computer-based tests (CBTs) are comparable to those of paper-and-pencil tests (PPTs) are still not answered". At a meeting of the American Educational Research Association (AERA) in San Antonio, Texas, the researchers from the American Association for the Advancement of Science (AAAS) Project 2061 presented findings from their study of comparing student performance on science tests administered in PPTs and CBTs formats. The study examined test results for a population of more than 33,000 students in grades 4 through 12 . The study compared student performance on tests administered using three testing systems: PPT and two CBT systems. Tests that assessed 4th through 12th-grade students' understanding of energy concepts were administered using each testing system. A comparison of students from each testing group was done using a quasi-experimental design in which propensity score matching was used to form demographically similar groups for each testing modality. Rasch analysis was used to estimate item- and student-level measures. Students' performances from different testing modalities were compared to evaluate whether PPT and CBT yielded equal measures of student knowledge.

"Ref. [4]" evaluated students' academic performance in JAMB chemistry test written using computer-based test (CBT) and paper-pencil media in Delta State University. Five research questions were raised and answered, and five null hypotheses were formulated and tested and were used to guide the study. Ex-Post facto were used, $10 \%$ of the total populations were used which is 2098 students" result scores for 2012 and 2015. The instrument used is chemistry JAMB raw scores for both years results. Experts from JAMB and the Department of Guidance and Counselling (Measurement and Evaluation) at Delta State University validated the instruments. JAMB experts did the reliability with a reliability coefficient of 0.83 for paper pencil test and 0.87 for computer-based testing. They used the mean to carry out the analysis of the data to calculate the research questions, and Z-test statistic was used to calculate the hypothesis. The findings revealed that there was a significant difference between the students' academic performance in computer-based test and paper-pencil testing in JAMB chemistry for Delta State University. Their results showed that the students perform better with the use of computer-based testing than the paper-pencil media in Delta State University. From their findings, they recommended the use of computer-based testing since students performed better and this has proven $100 \%$ elimination of all form of examination malpractice.

"Ref. [19]" researched Student Performance on Computer-Based Tests Versus Paper-Based Tests in Introductory Financial Accounting course in the U.A.E. The study examined if the usage of technology-based assessment tool affects the examinations' scores of students from both genders. The study established whether the mode of student testing (computer-based or paper-based) in an introductory-level financial accounting course obstructed students' scores. In doing so, the study relied on experimental design wherein the type of examination is being controlled together with some other variables such as the timing of the exam, instructors, and the gender of students. The sample of study consisted of 78 students who registered financial accounting courses at Zayed University during the summer semester. A simple difference in means statistics test was used for analysis where the result showed that there was no statistically significant difference between the students' paper-based and computer-based scores. However, using the benchmark regression analysis, it showed that females performed better than males on PBT, and males 
outperformed females on CBT. Therefore, based on the findings, this study provided evidence from the Gulf region as to how technology-based assessment is affected by the gender, which needs to be addressed by university instructors in Middle East universities.

There appear to be no available pieces of research available to assess students' academic performance using entry requirements under the computer-based test and paper pencil test. One major shortcoming of all reviewed studies is using only one particular course in a tertiary institution to test academic performance. The reviewed studies by $[16,17,18,15,19]$ all dealt with matters related to computer-based test and paper-pencil test in different parts of the world using only one particular course in a tertiary institution. However, the study by [4] considered one subject, chemistry, in the UTME examination for candidates who applied for admission into Delta State University.

Therefore, this study intends to find out whether firstyear students admitted into any of the mathematicalscience based programmes at the Kaduna State University using the PPT in the JAMB UTME perform academically better than their counterparts who used the CBT.

\section{Methodology}

Research methodology is an essential component of any research because it renders the opportunity to other researchers to replicate the study to ensure that similar results are obtained. Research methodology refers to the step-by-step approach to solve a particular research problem. According to [20], methodology involves justification of why a particular technique or method has been used, how has the process been carried out and a lot more.

This section presents the information about the research design, population of study, sample technique, the procedures for data collection, and the data analysis that guided this study.

\section{A. Research Design}

This study adopted the quantitative approach of research. Quantitative methods assist with the meticulous and organised collection, ordering, description and interpretation of data. "Ref. [21]" supported the notion of quantitative research as it investigates the behaviour, procedures of interaction, meanings, values and experiences of purposefully sampled individuals and groups in their natural context.

\section{B. Population of Study}

The Kaduna State University currently runs twentynine undergraduate programmes within seven faculties namely Arts, Sciences, Social and Management Science, Medicine, Pharmacy, Environmental, and Agriculture. The university has admitted a total number of 22,763 students into various undergraduate programmes since its inception in 2005.

The target population for this study is homogenous which comprised of 1,456 students admitted from
2010/2011 to 2016/2017 academic sessions into any of the mathematical science-based undergraduate programmes such as Computer Science, Mathematics and Physics. The target population distribution for the mathematical science-based undergraduate programmes is as shown in Table 1 and summarized in Fig. 1.

\section{Sample and Sampling Techniques}

A sample is a portion selected for study from a broadly defined population. Sample as defined by [22] is "a group of a relatively smaller number of people selected from a population for investigation purpose". Sampling, on the other hand, is the process through which a sample is extracted from a population. The sample chosen for this study were 578 students that sat for UTME using PPT between 2010 to 2012 and 445 students who wrote the UTME using the CBT between 2015 and 2016. The method used for selection was the purposive sampling technique - this involved selection of students based on complete required data such as gender, date of birth, state of origin, UTME and first-year end-of-session CGPA results.

\section{Instruments for Data Collection}

The research instruments used to obtain data for the study were the JAMB UTME scores from 2010 to 2016 and first-year CGPA results obtained from the semester examinations from 2010/2011 to 2016/2017 academic sessions respectively.

\section{E. Procedure for Data Collection}

Data collection procedure followed the norms of fieldwork research. Two types of data were used for the study. One is the UTME scores obtained from the University's central database with the approval of the Deputy Director of Information and Communications Technology (ICT). The other is the academic standing of first-year CGPA results collected from various departmental examination officers (DEOs) with the approval from the Dean of Faculty of Science.

\section{F. Procedure for Data Analysis}

The process of data analysis involved data clean up, analysis and explanation. Frequency tables and percentages were used to present the findings. The UTME and CGPA were coded using the Likert scale as shown in Table 2. The data once coded was tabulated and processed with the aid of the most widely used and robust data analysis software, SPSS version 23, developed by International Business Machines (IBM) since 2009. SPSS is an acronym for Statistical Package for Social Sciences, but now it can also be referred to as Statistical Product and Service Solutions. It was used in this research study.

\section{Data Presentation, Analysis and Discussion}

This section describes the analysis of data followed by a discussion of the research findings. The findings relate to the research questions that guided the study. Data were analysed to identify whether the academic performance of 
students improve if the entrance examination that is JAMB UTME is conducted using either CBT or PPT.
The results of the analyses were displayed using visualisation tools such as tables and charts.

Table 1. Distribution of Students Admitted into Some Undergraduate Programmes in the Faculty of Science from 2010/2011 to $2016 / 2017$ Academic Sessions

\begin{tabular}{|c|c|c|c|c|c|c|c|c|}
\hline \multirow[b]{2}{*}{ Programme } & \multicolumn{7}{|c|}{ Academic Sessions } & \multirow[b]{2}{*}{ Total } \\
\hline & $2010 / 11$ & 2011/12 & $2012 / 13$ & $2013 / 14$ & $2014 / 15$ & $2015 / 16$ & $2016 / 17$ & \\
\hline Computer Science & 73 & 70 & 93 & 82 & 93 & 94 & 131 & 636 \\
\hline Mathematics & 77 & 56 & 65 & 68 & 48 & 46 & 92 & 452 \\
\hline Physics & 64 & 37 & 55 & 49 & 46 & 32 & 85 & 368 \\
\hline Total & 214 & 163 & 213 & 199 & 187 & 172 & 308 & 1456 \\
\hline \% Total & 14.7 & 11.2 & 14.6 & 13.7 & 12.8 & 11.8 & 21.2 & 100.0 \\
\hline
\end{tabular}

Source: Field Survey (2018).

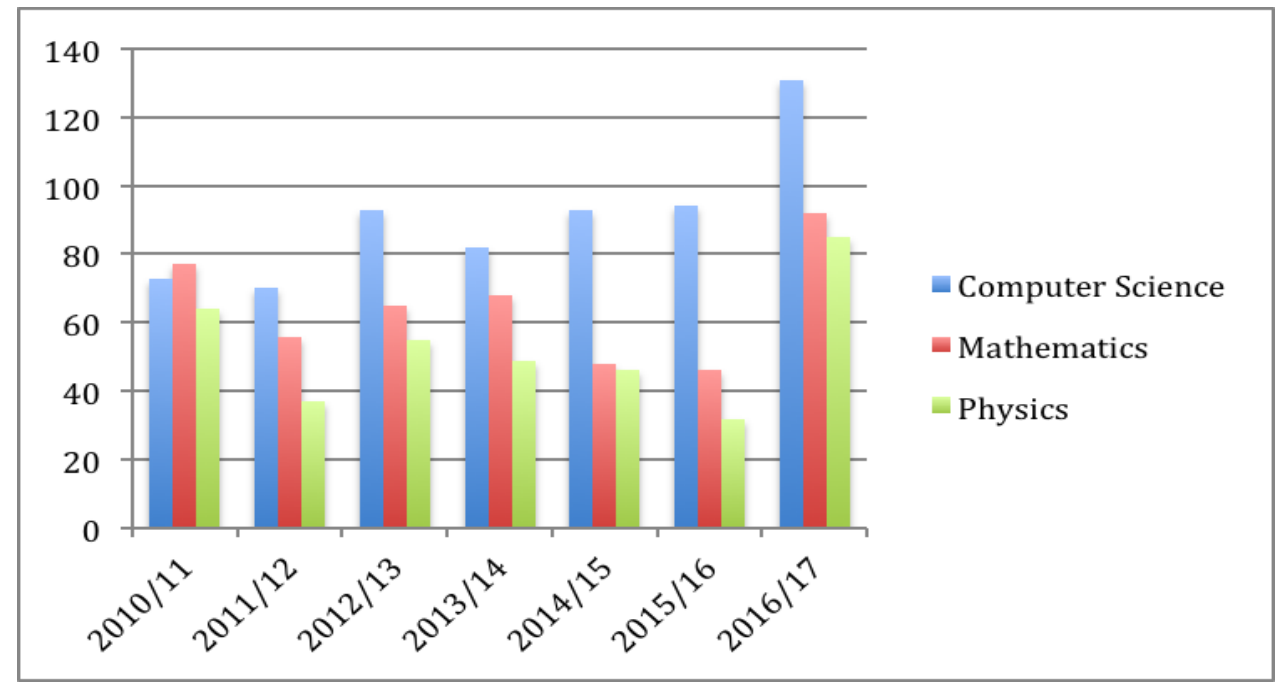

Fig.1. Students Distribution into Undergraduate Programmes from 2010/2011 to 2016/2017 Academic Sessions

Table 2. Coding Scale used for UTME and CGPA

\begin{tabular}{|c|c|c|c|c|c|c|}
\hline WEIGHTS & 0 & 1 & 2 & 3 & 4 & 5 \\
\hline UTME & $180-198$ & $199-216$ & $217-234$ & $235-252$ & $253-288$ & $289-300$ \\
\hline CGPA & $0.00-0.99$ & $1.00-1.49$ & $1.50-2.39$ & $2.40-3.49$ & $3.50-4.49$ & $4.50-5.00$ \\
\hline
\end{tabular}

Source: Field Survey (2018).

Table 3. Demographic Characteristics of Students by Group and Academic Sessions $(n=1023)$

\begin{tabular}{|c|c|c|c|c|c|c|c|c|}
\hline \multirow[t]{2}{*}{ Characteristic } & \multirow[t]{2}{*}{ Group } & \multicolumn{7}{|c|}{ Number } \\
\hline & & $2010 / 11$ & $2011 / 12$ & $2012 / 13$ & $2015 / 16$ & $2016 / 17$ & $\begin{array}{c}\text { Total } \\
\text { (Frequency) }\end{array}$ & $\begin{array}{c}\% \\
\text { Total }\end{array}$ \\
\hline \multirow{2}{*}{ Gender } & Female & 42 & 26 & 28 & 33 & 56 & 185 & 18.1 \\
\hline & Male & 170 & 135 & 177 & 127 & 229 & 838 & 81.9 \\
\hline \multirow{2}{*}{ Indigene } & Kaduna State & 177 & 145 & 191 & 134 & 250 & 897 & 87.7 \\
\hline & Other State & 35 & 16 & 14 & 26 & 35 & 126 & 12.3 \\
\hline \multirow{4}{*}{ Age Group } & $<18$ Years & 15 & 3 & 12 & 23 & 48 & 101 & 9.9 \\
\hline & $18-25$ Years & 186 & 143 & 177 & 127 & 218 & 851 & 83.2 \\
\hline & 26-30 Years & 7 & 13 & 14 & 7 & 17 & 58 & 5.7 \\
\hline & $>30$ Years & 4 & 2 & 2 & 3 & 2 & 13 & 1.3 \\
\hline \multirow{5}{*}{ UTME Scores } & $180-198$ & 86 & 79 & 69 & 107 & 202 & 543 & 53.1 \\
\hline & $199-216$ & 63 & 52 & 58 & 32 & 59 & 264 & 25.8 \\
\hline & $217-234$ & 32 & 19 & 45 & 16 & 14 & 126 & 12.3 \\
\hline & $235-252$ & 23 & 7 & 26 & 4 & 8 & 68 & 6.6 \\
\hline & $253-288$ & 8 & 4 & 7 & 1 & 2 & 22 & 2.2 \\
\hline \multirow{6}{*}{ CGPA } & $0.00-0.99$ & 4 & 5 & & & 15 & 24 & 10.7 \\
\hline & $1.00-1.49$ & 58 & 36 & 46 & 4 & 75 & 219 & 13.1 \\
\hline & $1.50-2.39$ & 72 & 59 & 79 & 42 & 95 & 347 & 30.4 \\
\hline & $2.40-3.49$ & 45 & 40 & 55 & 58 & 70 & 268 & 29.7 \\
\hline & $3.50-4.49$ & 25 & 20 & 21 & 46 & 26 & 138 & 13.5 \\
\hline & $4.50-5.00$ & 8 & 1 & 4 & 10 & 4 & 27 & 2.6 \\
\hline \multirow{2}{*}{ Test Medium } & PPT & 214 & 163 & 213 & & & 578 & 56.5 \\
\hline & CBT & & & & 172 & 308 & 445 & 43.5 \\
\hline
\end{tabular}

Source: Field Survey (Researchers' computation using SPSS, 2018). 

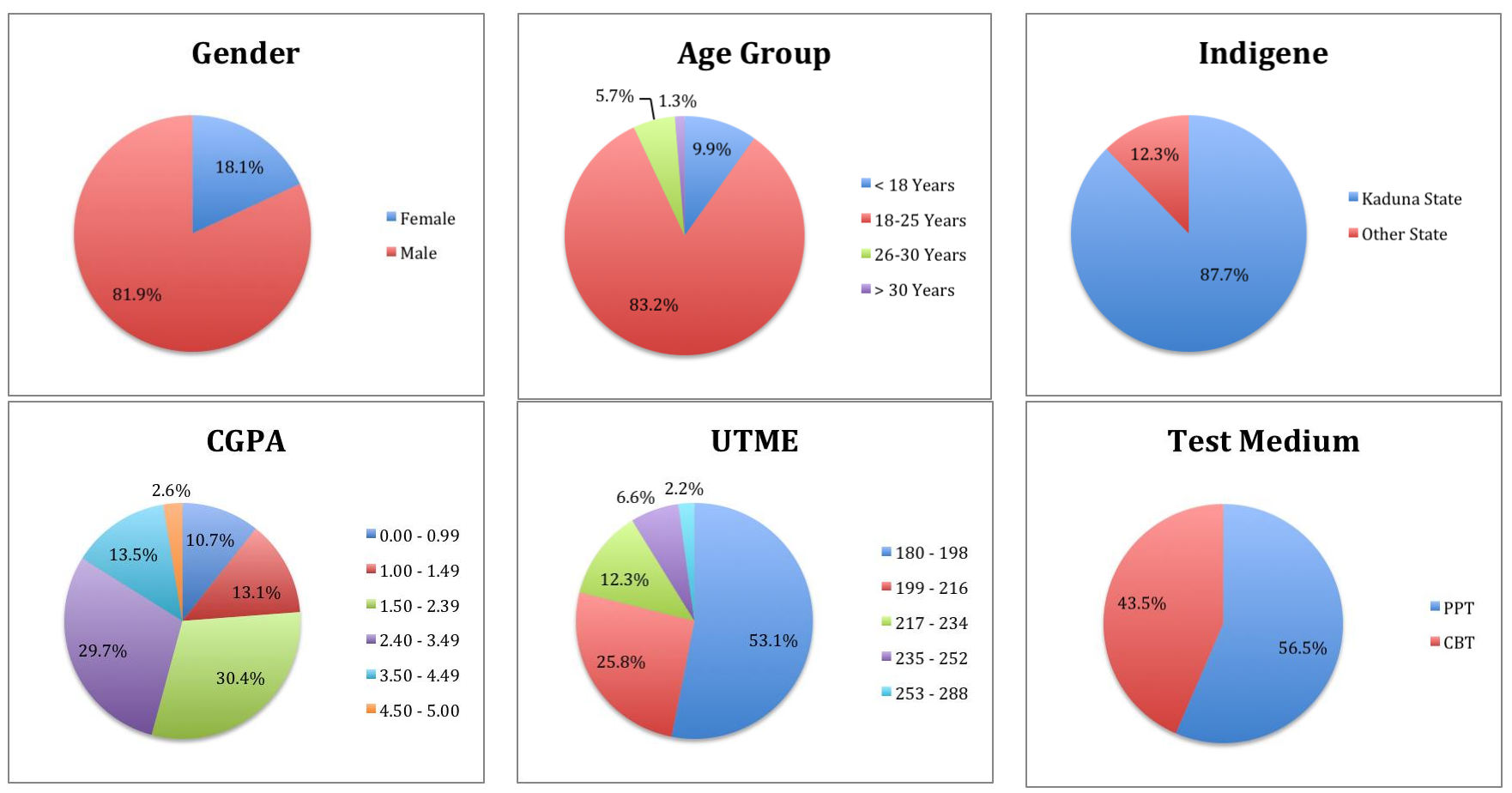

Fig.2. Percentage distribution of students based on Gender, Indigene, Age Group, UTME, CGPA and Test Medium (Source: Researchers' computation, 2018)

\section{A. Methods of Data Analysis and Presentation of Data}

Descriptive statistical analysis was used to identify frequencies and percentages for the six demographic characteristics used in this research study. The demographic characteristics are gender, age, indigene, test medium, academic standing (CGPA) and UTME scores. The frequencies and percentages of all students for each academic session in each of the demographic variables are as shown in Table 3 and summarized in Fig. 2.

The results of the study in Table 3 indicate that most $(81.9 \%)$ of the students were males whilst $18.1 \%$ were females. The majority $(83.2 \%)$ of the students were between the ages of 18 to 25 and $9.9 \%$ were below the age of 18. This suggests that most of the students were at the appropriate age for tertiary education.

Most $(87.7 \%)$ were from Kaduna State while $12.3 \%$ are from other states. This indicates that the University adheres to the strict admission exercise guidelines with the National Policy on Education (NPC).

$578(44 \%)$ students from the sample of the study wrote the UTME using PPT while 445 (56\%) wrote using the CBT.

Majority of the students studying any of the mathematical sciences-based undergraduate degree programmes scored between 180-198 in their UTME, which constituted $53.1 \%$ of the sample population. This is followed by $25.8 \%$ of the students of the sample, who scored between 199-216. This suggests that the performance is averagely on the low side and there is need for improvement.

The academic standing of students is usually measured using the Cumulative Grade Point Average (CGPA) on a 5-point scale in Nigerian tertiary institutions. The class of degree such as "First Class", "Second Class Upper", "Second Class Lower", "Third Class" and "Pass" determines the academic performance of a student at the end of the study of a degree programme. Each of these classes depends on the CGPA earned by the student. In this study, the CGPA at the end of the first academic year of study is used. Majority of the students, $30.4 \%$, at the end of their first year of study have their CGPA falling within the range of $1.50-2.39$, which is the "Third Class" group. This is followed by $29.7 \%$ who fall within the 2.40-3.49 group which is the "Second Class Lower" group. Approximately $2.6 \%$ of the students are within the 4.50-5.00 group which represents the "First Class" degree. A total of 243 students $(23.8 \%)$ are within the 0.00-0.99 and 1.00-1.49 which represents the "Fail" and "Pass" degrees respectively. This suggests that the overall performance of the students in their first year is generally poor as a result of low UTME performance.

\section{B. Discussion of Findings}

This section presents the findings for the four research questions that were raised.

Analysis of Variance (ANOVA) was also used to present answers to the research questions in the study. ANOVA was done to find out the relation between the demographic variables and the academic performance of students. The level of significance was set at $5 \%$.

1. Research Question 1 - Is there a significant difference in students' academic performance by using either of the testing methods, CBT or PPT in JAMB UTME for Kaduna State University?

Table 4 provides useful descriptive statistics including the mean, standard deviation and $95 \%$ confidence levels 
for the dependent variable, CGPA, for each separate group, that is, CBT and PPT. Table 5 shows the output of the ANOVA analysis used to test the research question. The CBT and PPT were the test medium used and based on the values obtained from the descriptive statistics, the $F$ value was obtained.

As shown in Table 5, the significance level is 0.008 , which is less than 0.05 , and this means that there is a statistically significant difference between the test medium concerning academic performance. As indicated in Table 4, Students who used the PPT (2.4368) in the UTME has a better academic performance than their counterparts, CBT (2.2585) which is as illustrated in Fig. 3.
2. Research Question 2 - Is there a significant difference between male and female students' academic performance by using either of the testing methods, that is CBT or PPT in JAMB UTME for Kaduna State University?

Table 6 provides useful descriptive statistics including the mean, standard deviation and $95 \%$ confidence levels for the dependent variable, CGPA, for each separate group, that is, CBT and PPT for male and female students Table 7 shows the output of the ANOVA analysis used to test the research question.

Table 4. Descriptive Statistics For Significant Difference Among Test Medium To Academic Performance

\begin{tabular}{|c|c|c|c|c|c|c|c|c|}
\hline & \multirow[b]{2}{*}{$\mathrm{N}$} & \multirow[b]{2}{*}{ Mean } & \multirow[b]{2}{*}{ Std. Deviation } & \multirow[b]{2}{*}{ Std. Error } & \multicolumn{2}{|c|}{ 95\% Confidence Interval for Mean } & \multirow[b]{2}{*}{ Minimum } & \multirow[b]{2}{*}{ Maximum } \\
\hline & & & & & Lower Bound & Upper Bound & & \\
\hline CBT & 578 & 2.2585 & 1.00479 & .04179 & 2.1764 & 2.3406 & .05 & 4.93 \\
\hline PPT & 445 & 2.4368 & 1.12296 & .05323 & 2.3322 & 2.5415 & .04 & 4.86 \\
\hline Total & 1023 & 2.3361 & 1.06098 & .03317 & 2.2710 & 2.4012 & .04 & 4.93 \\
\hline
\end{tabular}

Source: Field Survey (Researchers' computation using SPSS, 2018).

Table 5. ANOVA For Significant Difference Among Test Medium Concerning Academic Performance

\begin{tabular}{|c|c|c|c|c|c|}
\hline & & & & & \\
& Sum of Squares & Df & Mean Square & F & Sig. \\
\hline Between Groups & 7.996 & 1 & 7.996 & 7.146 & .008 \\
Within Groups & 1142.448 & 1021 & 1.119 & & \\
Total & 1150.445 & 1022 & & & \\
\hline
\end{tabular}

Source: Field Survey (Researchers' computation using SPSS, 2018).

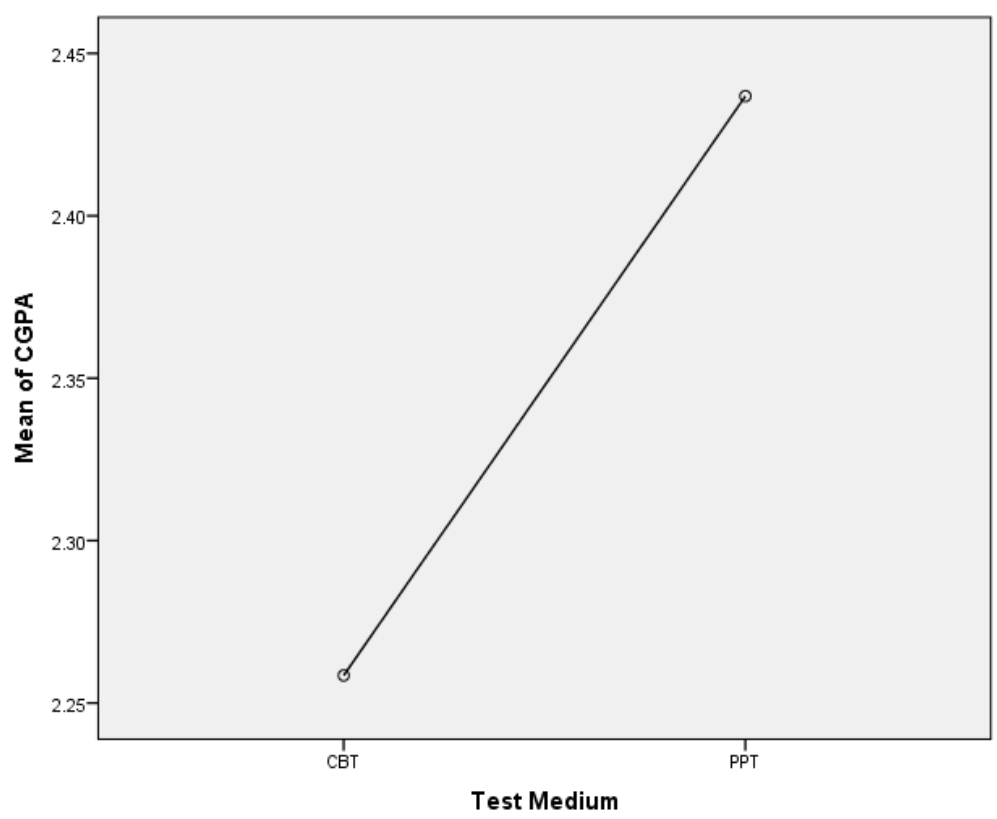

Fig.3. Mean Plot for significant difference among test medium concerning academic performance 
The significance values as shown in Table 7 are 0.064 and 0.020 for the male and female gender. However, for the male gender, there is no significant difference between the CBT and PPT concerning the male gender, whereas there is a difference for the female gender.

In Table 6, the mean for the CBT and PPT for the male gender is 2.28 and 2.42 , and their respective standard deviations are 1.00 and 1.13. Meanwhile, the mean for the CBT and PPT for the female gender is 2.15 and 2.51, and their standard deviations are 1.02 and 1.10. From all indications, for both the male and female gender, students who used PPT in the UTME performed better academically as shown in Fig. 4 respectively.

Table 6. Descriptive Statistics for the significant difference between the testing medium concerning gender

\begin{tabular}{|c|c|c|c|c|c|c|c|c|c|}
\hline \multirow{2}{*}{\multicolumn{2}{|c|}{ Gender }} & \multirow[b]{2}{*}{$\mathrm{N}$} & \multirow[b]{2}{*}{ Mean } & \multirow[b]{2}{*}{ Std. Deviation } & \multirow[b]{2}{*}{ Std. Error } & \multicolumn{2}{|c|}{ 95\% Confidence Interval for Mean } & \multirow[b]{2}{*}{ Minimum } & \multirow[b]{2}{*}{ Maximum } \\
\hline & & & & & & Lower Bound & Upper Bound & & \\
\hline \multirow[t]{3}{*}{ Male } & CBT & 482 & 2.2807 & 1.00103 & .04560 & 2.1911 & 2.3703 & .09 & 4.78 \\
\hline & PPT & 356 & 2.4177 & 1.12956 & .05987 & 2.3000 & 2.5354 & .04 & 4.86 \\
\hline & Total & 838 & 2.3389 & 1.05906 & .03658 & 2.2671 & 2.4107 & .04 & 4.86 \\
\hline \multirow[t]{3}{*}{ Female } & CBT & 96 & 2.1472 & 1.02152 & .10426 & 1.9402 & 2.3542 & .05 & 4.93 \\
\hline & PPT & 89 & 2.5134 & 1.09908 & .11650 & 2.2818 & 2.7449 & .38 & 4.76 \\
\hline & Total & 185 & 2.3234 & 1.07245 & .07885 & 2.1678 & 2.4789 & .05 & 4.93 \\
\hline
\end{tabular}

Source: Field Survey (Researchers computation using SPSS, 2018).

Table 7. ANOVA for the significant difference between the testing medium concerning gender

\begin{tabular}{|cc|c|c|c|c|c|}
\hline & & & & & \\
& Gender & Sum of Squares & df & Mean Square & F & Sig. \\
\hline Male & Between Groups & 3.845 & 1 & 3.845 & 3.438 & .064 \\
& Within Groups & 934.936 & 836 & 1.118 & & \\
Total & 938.782 & 837 & & & \\
\hline Female & Between Groups & 6.193 & 1 & 6.193 & 5.517 & .020 \\
\cline { 2 - 7 } & Within Groups & 205.434 & 183 & 1.123 & & \\
& Total & 211.627 & 184 & & & \\
\hline
\end{tabular}

Source: Field Survey (Researchers' computation using SPSS, 2018).
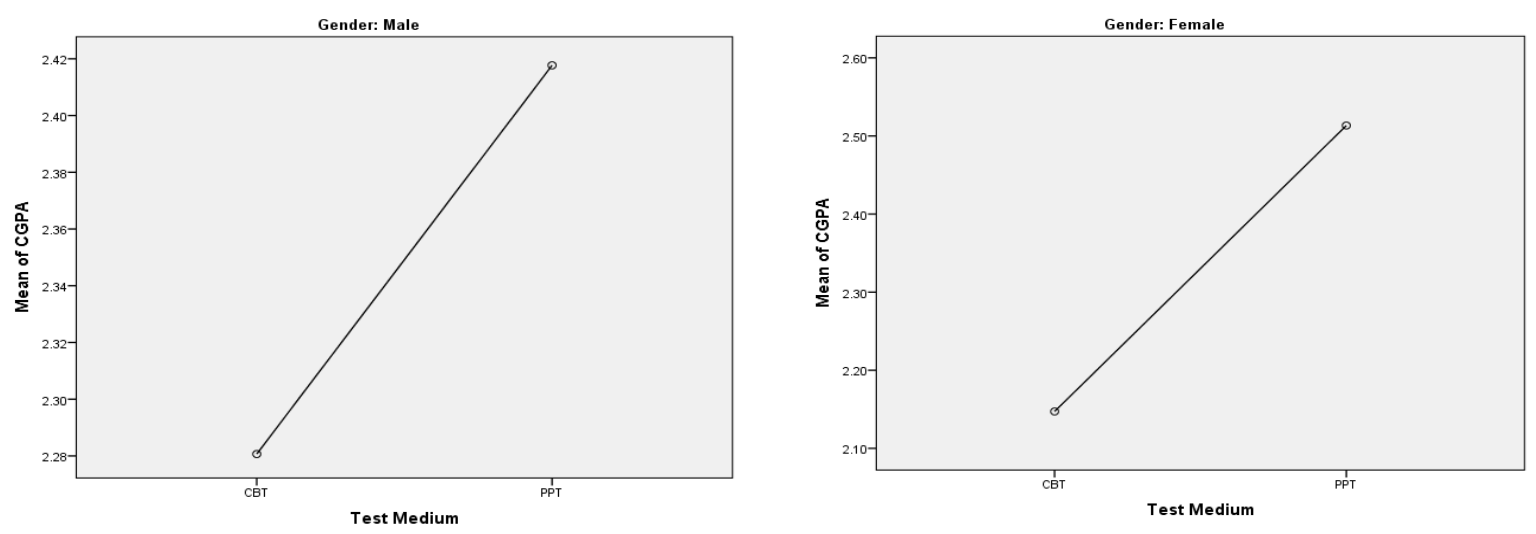

Fig.4. Mean Plot for significant difference among test medium concerning the male and female gender

3. Research Question 3 - Is there a significant difference between Kaduna State indigene and NonKaduna State indigene students" academic performance by using either of the testing methods, that is CBT or PPT in JAMB UTME for Kaduna State University?
Table 8 provides useful descriptive statistics including the mean, standard deviation and 95\% confidence levels for the dependent variable, CGPA, for each separate group, that is, CBT and PPT for Kaduna State indigenes and Non-Kaduna State indigenes students. Table 9 shows the output of the ANOVA analysis used to test the research question. 
The significance values as shown in Table 9 are 0.055 and 0.036 for the Kaduna State and Other State indigenes. However, for the Kaduna State indigenes, there is no significant difference between the CBT and PPT, but as for those from the Other States, there is a difference.

In Table 8, the mean for the CBT and PPT for Kaduna State indigenes is 2.26 and 2.39 , and their respective standard deviations are 0.98 and 1.11. Meanwhile, the mean for the CBT and PPT for the Non-Kaduna State (Other States) indigenes is 2.28 and 2.73, and their standard deviations are 1.21 and 1.18. From all indications as illustrated in Fig. 5, using the mean, for both Kaduna State and Other State indigene students who used PPT performed better academically.

Table 8. Descriptive Statistics For The Significant Difference Between The Testing Medium Concerning Indigene

\begin{tabular}{|c|c|c|c|c|c|c|c|c|c|}
\hline \multirow{2}{*}{\multicolumn{2}{|c|}{ Indigene }} & \multirow[b]{2}{*}{$\mathrm{N}$} & \multirow[b]{2}{*}{ Mean } & \multirow[b]{2}{*}{ Std. Deviation } & \multirow[b]{2}{*}{ Std. Error } & \multicolumn{2}{|c|}{ 95\% Confidence Interval for Mean } & \multirow[b]{2}{*}{ Minimum } & \multirow[b]{2}{*}{ Maximum } \\
\hline & & & & & & Lower Bound & Upper Bound & & \\
\hline \multirow[t]{3}{*}{ Kaduna State } & CBT & 513 & 2.2556 & .97775 & .04317 & 2.1708 & 2.3404 & .09 & 4.78 \\
\hline & PPT & 384 & 2.3900 & 1.10783 & .05653 & 2.2788 & 2.5012 & .04 & 4.85 \\
\hline & Total & 897 & 2.3132 & 1.03698 & .03462 & 2.2452 & 2.3811 & .04 & 4.85 \\
\hline \multirow[t]{3}{*}{ Other State } & CBT & 65 & 2.2811 & 1.20568 & .14955 & 1.9823 & 2.5798 & .05 & 4.93 \\
\hline & PPT & 61 & 2.7316 & 1.18117 & .15123 & 2.4291 & 3.0342 & .69 & 4.86 \\
\hline & Total & 126 & 2.4992 & 1.21040 & .10783 & 2.2858 & 2.7126 & .05 & 4.93 \\
\hline
\end{tabular}

Source: Field Survey (Researchers' computation using SPSS, 2018).

Table 9. ANOVA For The Significant Difference Between The Testing Medium Concerning Indigeneship

\begin{tabular}{|c|c|c|c|c|c|c|}
\hline \multicolumn{2}{|c|}{ Indigene } & Sum of Squares & $\mathrm{df}$ & Mean Square & $\mathrm{F}$ & Sig. \\
\hline \multirow[t]{3}{*}{ Kaduna State } & Between Groups & 3.965 & 1 & 3.965 & 3.698 & .055 \\
\hline & Within Groups & 959.522 & 895 & 1.072 & & \\
\hline & Total & 963.487 & 896 & & & \\
\hline \multirow[t]{3}{*}{ Other State } & Between Groups & 6.388 & 1 & 6.388 & 4.482 & .036 \\
\hline & Within Groups & 176.745 & 124 & 1.425 & & \\
\hline & Total & 183.133 & 125 & & & \\
\hline
\end{tabular}
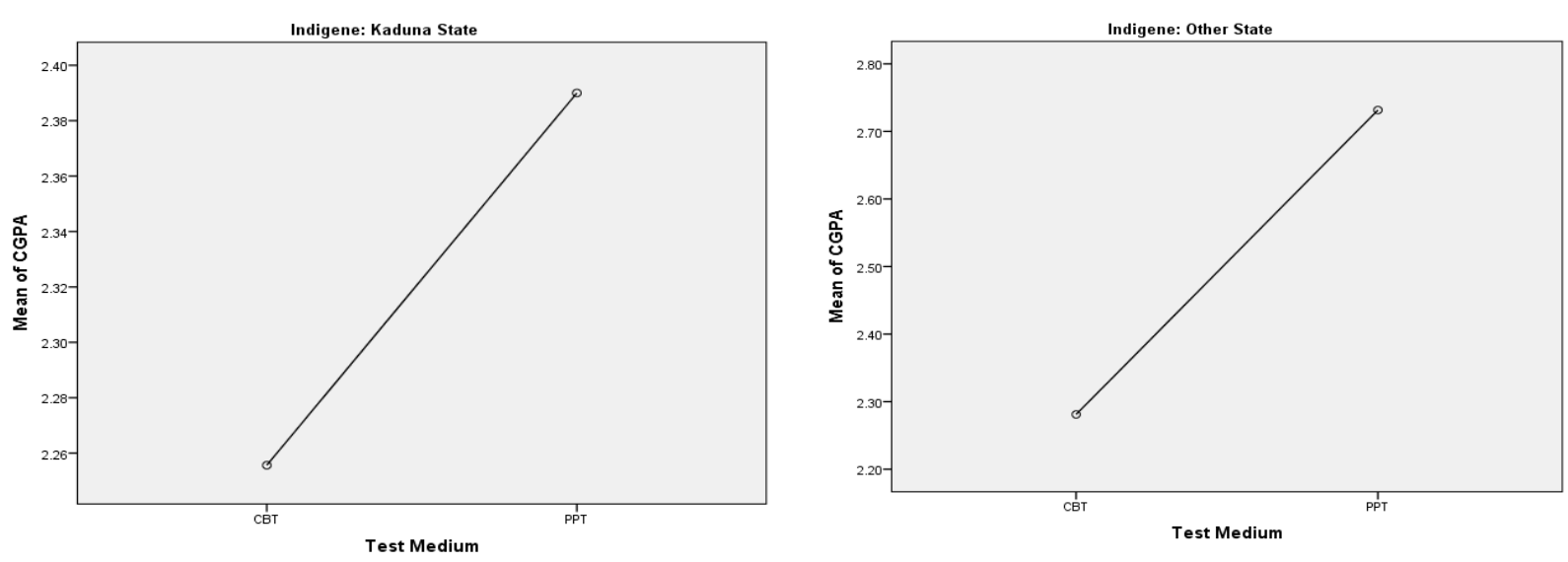

Fig.5. Mean Plot for significant difference among test medium concerning indigenes of Kaduna State and Others States

4. Research Question 4 - Is there a significant difference between the academic performance of students in various age groups by using either of the testing methods, that is CBT or PPT in JAMB UTME for Kaduna State University?
Table 10 provides useful descriptive statistics including the mean, standard deviation and 95\% confidence levels for the dependent variable, CGPA, for each separate group, that is, CBT and PPT for the various age groups of students. Table 11 shows the output of the ANOVA analysis used to test the research question. 
Table 10. Descriptive Statistics for the Significant Difference between the Testing Medium Concerning Various Age Groups

\begin{tabular}{|c|c|c|c|c|c|c|c|c|c|}
\hline \multirow[b]{2}{*}{ Age Grou } & & \multirow[b]{2}{*}{$\mathrm{N}$} & \multirow[b]{2}{*}{ Mean } & \multirow[b]{2}{*}{ Std. Deviation } & \multirow[b]{2}{*}{ Std. Error } & \multicolumn{2}{|c|}{ 95\% Confidence Interval for Mean } & \multirow[b]{2}{*}{ Minimum } & \multirow[b]{2}{*}{ Maximum } \\
\hline & & & & & & Lower Bound & Upper Bound & & \\
\hline \multirow[t]{3}{*}{ Below 18 years } & CBT & 30 & 2.4363 & .96442 & .17608 & 2.0762 & 2.7965 & 1.00 & 4.93 \\
\hline & PPT & 71 & 2.2793 & 1.08180 & .12839 & 2.0232 & 2.5354 & .20 & 4.86 \\
\hline & Total & 101 & 2.3259 & 1.04601 & .10408 & 2.1194 & 2.5324 & .20 & 4.93 \\
\hline \multirow[t]{3}{*}{$18-25$ years } & CBT & 506 & 2.2452 & .99845 & .04439 & 2.1580 & 2.3324 & .05 & 4.78 \\
\hline & PPT & 345 & 2.4873 & 1.12664 & .06066 & 2.3680 & 2.6066 & .04 & 4.76 \\
\hline & Total & 851 & 2.3433 & 1.05836 & .03628 & 2.2721 & 2.4145 & .04 & 4.78 \\
\hline \multirow[t]{3}{*}{$26-30$ years } & CBT & 34 & 2.1903 & .98725 & .16931 & 1.8458 & 2.5348 & .50 & 4.40 \\
\hline & PPT & 24 & 2.1388 & 1.17964 & .24079 & 1.6406 & 2.6369 & .82 & 4.85 \\
\hline & Total & 58 & 2.1690 & 1.06134 & .13936 & 1.8899 & 2.4480 & .50 & 4.85 \\
\hline \multirow[t]{3}{*}{ Above 30 years } & CBT & 8 & 2.7250 & 1.55977 & .55146 & 1.4210 & 4.0290 & .09 & 4.60 \\
\hline & PPT & 5 & 2.6240 & 1.04713 & .46829 & 1.3238 & 3.9242 & 1.02 & 3.71 \\
\hline & Total & 13 & 2.6862 & 1.33690 & .37079 & 1.8783 & 3.4940 & .09 & 4.60 \\
\hline
\end{tabular}

Source: Field Survey (Researchers' computation using SPSS, 2018).

Table 11. ANOVA for the Significant Difference between the Testing Medium Concerning Various Age Groups

\begin{tabular}{|cc|r|r|r|r|r|}
\hline \multicolumn{2}{|c|}{ Age Group } & Sum of Squares & df & Mean Square & F & Sig. \\
\hline Below 18 years & Between Groups & .520 & 1 & .520 & .473 & .493 \\
& Within Groups & 108.894 & 99 & 1.100 & & \\
& Total & 109.414 & 100 & & & \\
\hline 18 - 25 years & Between Groups & 12.025 & 1 & 12.025 & 10.860 & .001 \\
\cline { 2 - 8 } & Within Groups & 940.083 & 849 & 1.107 & & \\
& Total & 952.108 & 850 & & & \\
\hline 26 - 30 years & Between Groups & .037 & 1 & .037 & .033 & .857 \\
\cline { 2 - 8 } & Within Groups & 64.170 & 56 & 1.146 & & \\
\hline Above 30 years & Between Groups & 64.207 & 57 & & & \\
\cline { 2 - 8 } & Within Groups & .031 & 1 & .031 & .016 & .901 \\
& Total & 21.416 & 11 & 1.947 & & \\
\hline
\end{tabular}

Source: Field Survey (Researchers' computation using SPSS, 2018).

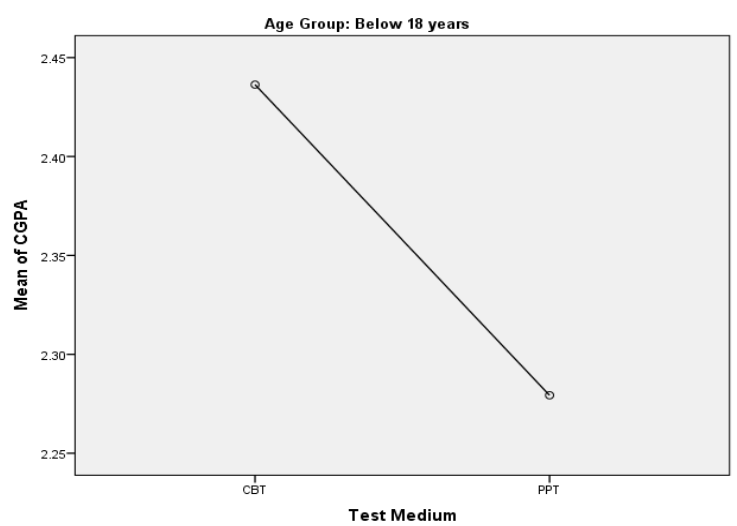

Copyright (C) 2019 MECS

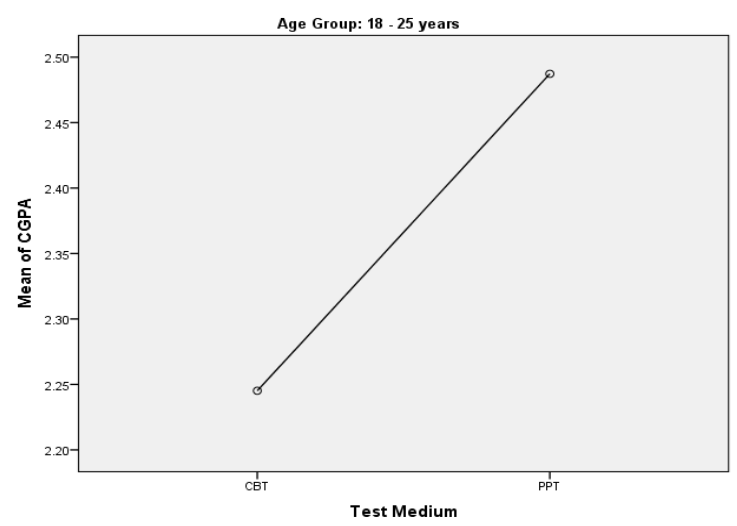

I.J. Modern Education and Computer Science, 2019, 8, 48-60 

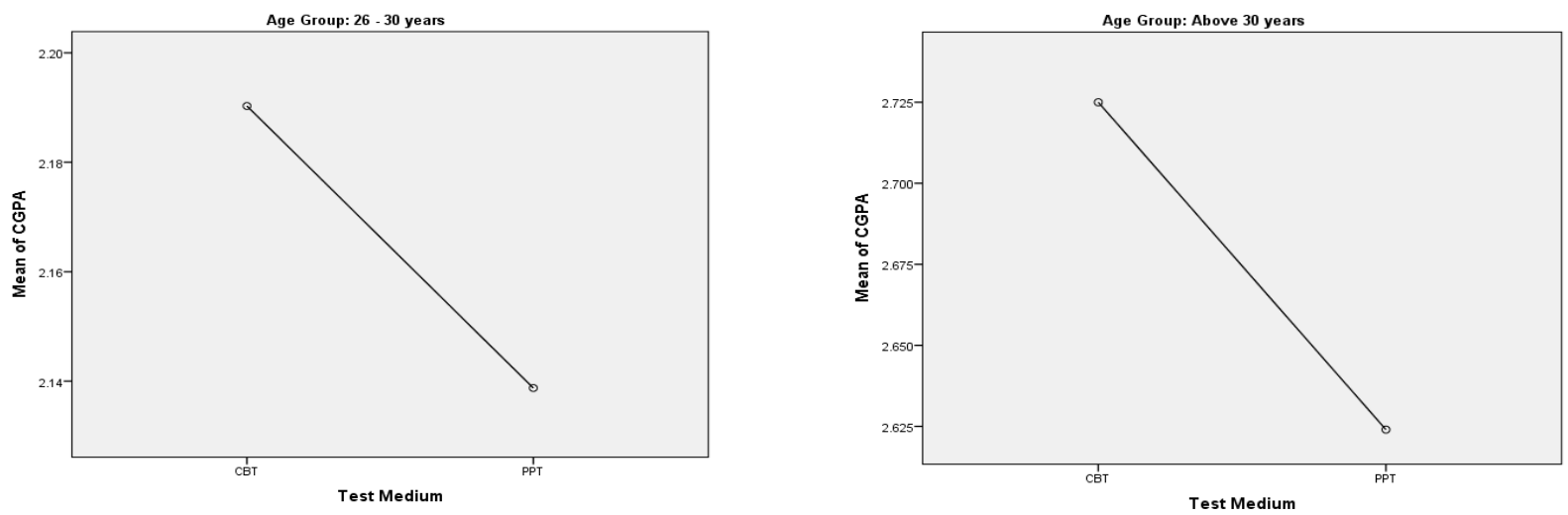

Fig.6. Mean Plot for significant difference among test medium concerning Age Group for above 30 years

The significant values for the various age groups are shown in Table 11 . Only the $18-25$ years age group has a significant value of less than 0.05 , and this shows that there is a significant difference between the CBT and PPT. As for the other age groups, the significant value is high therefore there is no significant difference between the CBT and PPT.

Table 10 shows the mean and standard deviations for the CBT and PPT in various age groups. The means are higher and lower in CBT and PPT for the various age groups - below 18 years, 26-30 years and above 30 years, which indicates, the students performed better academically using CBT respectively as shown in Fig. 6. Meanwhile, for the 18-25 years age group, the mean is lower in CBT than its PPT counterpart indicating that using PPT enhanced their academic performance.

\section{CONCLUSION}

The primary purpose of this study is to investigate if OL results, UTME and PUTME scores do predict the academic performance among first-year undergraduate students in the Faculty of Science. Based on the analysis and results using MLR and PPMC for each programme and each academic session, it is evident that OL, UTME or PUTME could not individually significantly predict the academic performance of students in Faculty of Science.

However, by combining all the criterion variables, that is OL, UTME, and PUTME, as one variable and performing the PPMC and MLR, findings show that OL is a good predictor on the dependent variable for academic performance with a weak correlation of 0.068 which is statistically significant at 0.04 level. This predictor holds true especially for students who are in the CGPA category of " $2^{\text {nd }}$ Class Lower" and " 1 st Class" respectively.

Although OL and UTME are still necessary as instruments for admission, it is recommended that the University be advised to include some other instruments such as senior secondary school mock examinations results for selecting candidates into any of the undergraduate degree programmes in the Faculty of Science. Also, there is a need to do a further study by including some more variables, such as age and senior secondary school mock examinations results, as criteria to significantly predict the academic performance of students successfully. In the study of [23], the authors also recommended the need of potential researchers to compare the OL, UTME and Post UTME terms and scores across Nigerian Universities for standardisation and a model for educational development in the twenty first century.

\section{REFERENCES}

[1] Mushtaq I, Khan SN. Factors Affecting Students' Academic Performance. Global Journal of Management and Business Research. 2012; 12(9): 16-22.

[2] Ali N, Jusoff K, Ali S, Mokhtar N, Salamat ASA. The Factors Influencing Students' Performance at Universiti Teknologi MARA Kedah, Malaysia. Management Science and Engineering. 2009; 3(4): 81-90.

[3] Magaji AS, Abdulkadir S, Peter A, Muhammad AA, Yushau IA. An Evaluation of Students' Admission Exercises (ESAE) in Kaduna State University, Nigeria. International Journal of Educational Sciences (IJES). 2013; 5(2): 131-5.

[4] Osadebe PU, Esegbue TO. Evaluation of Students Academic Performance in JAMB Chemistry Test under the Computer Based Testing and Paper Pencil Media in Delta State University. International Journal of Advanced Research (IJAR). 2018; 6(5): 415-26.

[5] Jamil M, Tariq RH, Shami PA. Computer-Based VS Paper-Based Examinations: Perceptions of University Teachers. The Turkish Online Journal of Educational Technology (TOJET). 2012; 11(4): 371-81.

[6] Abubakar AS, Adebayo FO. Using computer based test method for the conduct of examination in Nigeria: Prospects, challenges and strategies. Mediterranean journal of Social Sciences. 2014; 5(2): 47-55.

[7] Olumorin CO, Fakomogbon MA, Fasasi YA, Olawale CO, Olafare FO. Computer-Based Tests: A System of Assessing Academic Performance in University of Ilorin, Ilorin, Nigeria. American Academic \& Scholarly Research Journal. 2013; 5(2).

[8] Oluwasanumi AA. An Evaluation of the Challenges Encountered in the First General Computer Based Test in Nigeria. Pakistan Journal of Educational Research and Evaluation. 2016; 1(1):1-13.

[9] Olawale A, Shafil MA. E-Exams System for Nigerian Universities with Emphasis on Security and Result Integrity. In: Proceedings of the Seventh International 
Conference on eLearning for Knowledge-Based Society. Bangkok Metropolitan Area, Thailand: International Journal of the Computer, the Internet and Management; 2010. p. 47.1.

[10] Ayuba P. Comparative Analysis of Post University Matriculation Examination in Nigerian Universities Using Fuzzy Logic. British Journal of Mathematics \& Computer Science (BJMCS). 2015; 11(6): 1-10.

[11] Bridgeman B, Lennon ML, Jackenthal A. Effects of Screen Size, Screen Resolution, and Display Rate on ComputerBased Test Performance. Applied Measurement in Education. 2003; 16(3): 191-205.

[12] Choi SW, Tinkler T. Evaluating comparability of paperand-pencil and computer-based assessment in a K-12 setting. 2002 Annual Meeting of the National Council on Measurement in Education; 2002.

[13] Hetter AL, Segall DO, Bloxom BM. A Comparison of Item Calibration Media in Computerized Adaptive Testing. Applied Psychological Measurement. 1994; 18(3): 197204.

[14] Gallengher A, Bridgeman B, Cahalan C. The Effect of Computer-Based Tests On Racial/Ethnic, Gender, and Language Groups. 2000 p. 1-17. (ETS 14 Research Report Series).

[15] Hardcastle J, Herrmann-Abell CF, DeBoer GE. Comparing Student Performance on Paper-and-Pencil and ComputerBased-Tests. Paper presented at: American Educational Research Association; 2017; San Antonio, TX.

[16] Macrander C, Manansala R, Rawson S, Han JY. The difference in performance between computer and paper administered tests in a stressful environment. Journal of Advanced Student Science. 2012; 1.

[17] Ita ME, Kecskemety KM, Ashley KE, Morin B. Comparing Student Performance on Computer-Based vs. Paper-Based Tests in a First-Year Engineering Course. In: 121st ASEE Annual Conference \& Exposition. Indianapolis, Indiana; 2014.

[18] Hosseini M, Abidin MJZ, Baghdarnia M. Comparability of Test Results of Computer Based Tests (CBT) and Paper and Pencil Tests (PPT) among English Language Learners in Iran. Procedia - Social and Behavioral Sciences. 2014; 98: 659-67.

[19] Garas S, Hassan M. Student Performance on ComputerBased Tests Versus Paper-Based Tests in Introductory Financial Accounting: UAE Evidence. Academy of Accounting and Financial Studies Journal. 2018; 22(2): 114.

[20] Kothari CR. Research Methodology: Methods and Techniques. 2nd ed. New Delhi, India: New Age International (P) Limited; 2004.

[21] Kitto SC, Chesters J, Grbich C. Quality in Quantitative Research. The Medical Journal of Australia (MJA). 2008; 188(4): 243-6.

[22] Alvi MH. A Manual for Selecting Sampling Techniques in Research. 2016.

[23] Uhunmwuangho SO, Ogunbadeniyi O. The University Matriculation Examination as a Predictor of Performance in Post University Matriculation Examination: a Model for
Educational development in the 21st Century. African Research Review. 2014; 8(1): 99-111.

[24] Kumar A. Study of Academic Achievement, Values and Adjustment of Secondary School Students in Relation to Working Status of Mothers [PhD Thesis]. [Amritsar]: Guru Nanak Dev University; 2010.

\section{Authors' Profiles}

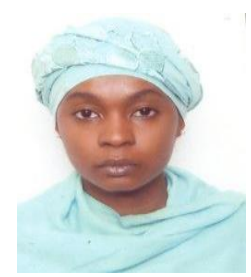

Sa'adatu Abdulkadir had her BTech in Computer Science and MSc in Informatics from the Abubakar Tafawa Balewa University (ATBU), Bauchi State and the University of Edinburgh, Scotland, United Kingdom. She is currently a $\mathrm{PhD}$ research student in Computer Science at the Nigerian Defence Academy (NDA), Kaduna State. She is a member of Computer Professional of Nigeria (CPN), British Computer Society (BCS), Nigerian Computer Society (NCS), Nigerian Mathematical Society (NMS) and International Computer Science and Engineering Society (ICSES).

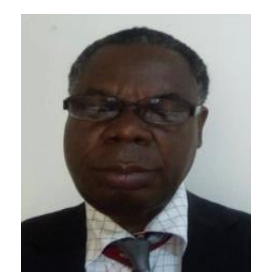

Professsor Emmanuel A. Onibere has a BSc in Mathematics from the University of Ibadan, MSc and PhD degrees from the University of Manchester and University of Aston in Birmingham respectively. Over the last decade, he has served as Head of Computer Science department and Director of Network Unit at the University of Benin. He also served as Director of Large Scale System Research group. He has served as Commonwealth Visiting Professor of Computer Science at the University of Buea, Cameroun. He has been Deputy Vice Chancellor at the University of Benin. He is well known and his research interests cover software engineering and human computer interaction. He is currently a Professor of Computer Science, and a Faculty Member at the University of Benin.

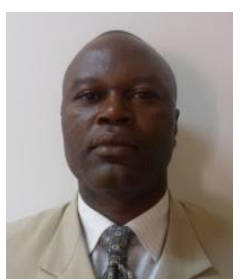

Dr. Philip O. Odion had his BSc in Computer Science from University of Benin, Benin City, Edo State. He obtained his MSc in Computer Science at Abubakar Tafawa Balewa University (ATBU), Bauchi and $\mathrm{PhD}$ in Computer Science at the Nigerian Defence Academy (NDA), Kaduna State. Dr. Odion is currently the Head of Department of Computer Science at the Nigerian Defence Academy, Kaduna State. He has various local and international publications to his credit. His research interests are in Software Engineering, Computer Networks and Artificial Intelligence.

How to cite this paper: Sa'adatu Abdulkadir, Emmanuel Amano Onibere, Philip Oshiokhaimhele Odion, "Assessment of Students' Academic Performance Using Admission Entry Requirements under the Computer-Based Test and PaperPencil-Based Test in Kaduna State University, Kaduna - Nigeria", International Journal of Modern Education and Computer Science(IJMECS), Vol.11, No.8, pp. 48-60, 2019.DOI: 10.5815/ijmecs.2019.08.06 